\title{
O PERCURSO CONCEPTUAL- TERMINOLÓGICO DE CURRÍCULO POR COMPETÊNCIAS NA EDUCAÇÃO PROFISSIONAL BRASILEIRA
}

\author{
Fernanda Mello DEMAI ${ }^{1}$
}

\begin{abstract}
Resumo: Currículo Escolar (em Educação Profissional Técnica) é definido como esquema teórico-metodológico que direciona o planejamento e o desenvolvimento de perfis profissionais e competências que atendam a objetivos de formação profissional, de acordo com as funções e demandas do mundo do trabalho e dos processos gerenciais e produtivos. O objetivo deste trabalho é demonstrar aspectos da terminologização da área de Currículo em Educação Profissional Técnica, bem como algumas relações entre terminologização e neologia. A criação de termos nasce da necessidade de "colocação" do conceito técnico e ou científico em termo, ou seja: a terminologização. Propomos um estudo do engendramento dos conceitos contrários: organização curricular por competências e organização curricular por conteúdos isolados, na reconfiguração da política curricular de Educação Profissional Técnica de Nível Médio que se deu a partir do paradigma dos anos 2000 no Brasil. Apresentamos também uma análise dos processos de terminologização que caracterizam alguns dos termos neológicos mais representativos da área, a exemplo de: currículo por competências; competências profissionais; bases tecnológicas. O corpus é constituído por textos legais, textos institucionais brasileiros e trabalhos de pesquisadores independentes. Partimos de algumas abordagens teóricometodológicas da Teoria Comunicativa da Terminologia e da Teoria Sociocognitiva da Terminologia.
\end{abstract}

Palavras-chave: Terminologia. Neologia. Terminologização. Análise Conceitual. Descrição Terminológica. Currículo Escolar em Educação Profissional Técnica.

\footnotetext{
${ }^{1}$ CEETEPS - Centro Estadual de Educação Profissional e Tecnológica Paula Souza; FAM - Faculdade das Américas. São Paulo - São Paulo - Brasil. 01305-100 - fernanda.demai@gmail.com
} 


\title{
Introdução
}

\begin{abstract}
Com a expressão vita activa, pretendo designar três atividades humanas fundamentais: trabalho, obra e ação. São fundamentais porque a cada uma delas corresponde uma das condições básicas sob as quais a vida foi dada ao homem na Terra. O trabalho é a atividade que corresponde ao processo biológico do corpo humano, cujos crescimento espontâneo, metabolismo $e$ consequente declínio estão ligados às necessidades vitais produzidas e fornecidas ao processo vital pelo trabalho. A condição humana do trabalho é a própria vida. (Hannah Arendt, A condição humana)
\end{abstract}

Considerar as relações entre currículo e cultura é primordial, observando-se a importância dos conhecimentos escolares (derivados e transpostos da Ciência e da Tecnologia), das demandas sociais e das ideologias envolvidas.

O currículo, como ato de correr, atalho, corte, já é documentado na língua portuguesa desde 1899 (CUNHA, 1986, p. 235). Para a formação do termo currículo (escolar, que ocorre na instituição escola), destacam-se os traços semânticos de atalho e de corte. Um conjunto de programas de ensino e suas consequentes organização e planejamento são escolhas possíveis em um universo maior - daí o sentido de corte, ou de recorte. Para os sentidos de atalho, destacam-se os traços de direcionamento eficiente, de um percurso mais eficaz e mais prazeroso em um caminho. Desses elementos de significação pode-se depreender que o currículo é (ou deve ser) um direcionamento preciso, uma condução por um caminho, que deve ser o menos tortuoso e mais certeiro para o alcance de objetivos.

Com Eagleton (2011, p. 9-11), observamos que a cultura também trata de recorte, ou de corte, de opções e de direcionamentos: “A ideia de cultura, então, significa uma dupla recusa: do determinismo orgânico por um lado, e da autonomia do espírito, por outro. É uma rejeição tanto do Naturalismo, como do Idealismo”.

A Cultura, ou essa in media res dialética entre Naturalismo e Idealismo, abrange as mais diversas práticas sociais, como a escola; o currículo escolar, como percurso, caminho tomado pelos atores educacionais para a consecução dos objetivos do Ensino, 
está atrelado ao conceito de cultura e, especialmente, ao de cultura ancorado social, histórica e ideologicamente.

Considerando os traços de ideologia ligados ao "controle dos comportamentos coletivos em determinada situação” (ABBAGNANO, 1970, p. 508), temos a relação tripartite currículo-cultura-ideologia, pois o currículo é um percurso construído (logo controlado) e escolhido por alguns atores sociais, em detrimento de outros percursos potenciais, por determinados motivos caros aos grupos que têm a condição social - e política - de optar por alguns elementos, recusando outros.

Sinteticamente, poderíamos afirmar que o currículo está ligado a uma escolha de percurso, com a recusa deliberada de outro(s), determinada e influenciada por quem tem condições e poder de escolher e de determinar o caminho de outrem, no âmbito de uma cultura, de uma sociedade, de um momento histórico e de um sistema de valores (ou de subconjuntos de sistemas de valores).

No recorte Educação, ressaltamos que currículo carrega o adjetivo escolar e que os atores sociais estão em função de atores educacionais. É do currículo escolar que trataremos para desenvolver as ideias apresentadas neste trabalho. Mais especificamente ainda, nosso tema é a área de Currículo Escolar em Educação Profissional Técnica de Nível Médio organizado pelas categorias “competências”.

Currículo Escolar (em Educação Profissional, subárea Educação Profissional Técnica de Nível Médio) é definido como esquema teórico-metodológico que direciona o planejamento e o desenvolvimento de perfis profissionais e competências que atendam a objetivos de formação profissional, de acordo com as funções e demandas do mundo do trabalho e dos processos produtivos e gerenciais (ARAÚJO; DEMAI; PRATA, 2016, p. 20).

O objetivo deste trabalho é demonstrar aspectos da terminologização da área de Currículo em Educação Profissional Técnica de Nível Médio, bem como algumas relações entre terminologização e neologia. 


\title{
Fundamentação, escolhas e proposições teórico-metodológicas
}

\begin{abstract}
A obra é a atividade correspondente à não neutralidade da existência humana, que não está engastada no sempre-recorrente ciclo vital da espécie e cuja mortalidade não é compensada por este último. A obra proporciona um mundo "artificial" de coisas, nitidamente diferente de qualquer ambiente natural. Dentro de suas fronteiras é abrigada cada vida individual, embora esse mundo se destine a sobreviver $e$ a transcender todas elas. A condição humana da obra é a mundanidade. (Hannah Arendt, A condição humana)
\end{abstract}

Apresentamos, nesta parte, alguns fundamentos sobre Terminologia e Neologia.

A Terminologia moderna ganhou vulto a partir dos anos de 1930, com as proposições de Eugen Wüster. Convencionou-se chamar a teoria de Wüster e de seus seguidores de Teoria Geral da Terminologia, doravante TGT. A TGT é caracterizada por uma natureza prescritiva e normativista e não por uma natureza descritiva, o que torna incoerente sua inclusão no âmbito dos estudos linguísticos.

Wüster negou teórica e metodologicamente a esfera do significado em relação a seu significante, negando também a influência discursiva na utilização das linguagens, incluindo as de especialidade.

A Terminologia pode ser encarada como o estudo dos conceitos, ou como o estudo dos termos, ou como o estudo do signo terminológico, com suas faces significante e significado indissociáveis, concepção esta última que adotamos.

Neologia, com outros autores, concebemos como o processo de criação de itens lexicais, os neologismos. Destacamos a conceituação de Alves (2006, p. 132)

Conceitua-se o neologismo, no Projeto TermNeo, como uma nova forma, uma nova acepção atribuída a uma unidade lexical ou um estrangeirismo recebido de uma outra língua. O neologismo, fortemente vinculado ao caráter social da linguagem, é sempre resultante de um fato social, que, em um determinado momento da história da sociedade, determina a criação de uma nova unidade lexical.

Consideramos a importância da neologia na vida em sociedade e também na concepção de vida individual, já que se constitui em um macroprocesso destinado à 
comunicação, sua função social e coletiva, mas que é também um recurso individual, praticamente de infinitas possibilidades de expressão e de manipulação linguística, recurso esse que está à disposição de todos os falantes de uma comunidade linguística.

\section{Relações entre terminologização e neologia}

A criação de termos (neologia terminológica) nasce da necessidade de "colocação" do conceito técnico e/ou científico em termo, ou seja: a terminologização (BARBOSA, 2007).

A neologia é criação de termos (em linguagens de especialidade) ou de palavras (na língua geral), e os neologismos são os produtos dessa criação, ou seja, as novas unidades linguísticas de caráter técnico e/ou científico. Consideramos então o neologismo um signo linguístico, que se caracteriza pelo seu aspecto inovador, em forma e/ou em conteúdo.

Em Terminologia, o processo da neologia acompanha as transformações técnicas, tecnológicas e científicas, pois novas realidades, novos produtos e novas tecnologias (novos conceitos) precisam de novos termos.

Conforme Barbosa (2007, p. 435-430), terminologização é o

[...] processo que converte conceito em termo, la mise en terme, expressão esta comparável à la mise en lexème, do processo de lexemização de Pottier. Nesse sentido, terminologização refere-se à relação entre o nível conceptual e o metalinguístico [...]. Ora, sabe-se que, dependendo da área técnica ou científica, os processos de terminologização lato sensu são muito mais amplos: o fonológico, o sintagmático, o semântico. O empréstimo (de uma língua para outra ou de uma área para outra) é apenas um dentre os vários processos de terminologização. [...]

No processo de passagem do conceptual para o terminológico, [há] a criação ex-nihilo, que terá graus diferentes de motivação, instauração de uma nova grandeza sígnica, numa combinatória inédita, no caso do processo fonológico e sintagmático [neológico]. O ponto de partida é o conceptual. [...]

Os processos de terminologização são profundamente ligados e dependentes da neologia. A terminologização diz respeito à colocação de um conceito na forma linguística de um termo, que precisa ser criado, de acordo com vários processos à disposição na língua, como o fonológico, o sintagmático, o semântico - na verdade, uma 
combinatória de processos, destacando-se um, como desencadeador da criação lexicalterminológica.

Consideramos terminologização um macroprocesso, um arquiconceito, que representa o protótipo (“traços comuns constantes nos 'recortes culturais'” - BARBOSA, 2001, p. 81) de passagem do nível conceptual para o linguístico, que reúne os traços comuns, com a neutralização das diferenças entre terminologização e metaterminologização.

Em suma, a metaterminologização é a passagem de unidades de uma terminologia para outra, com ou sem manutenção de traços semânticos, em que "se instaura um termo a partir de outro termo” (BARBOSA, 2007, p. 438), ou seja, o ponto de partida é linguístico, de um conjunto-vocabulário para outro.

Na terminologização lato sensu, o que se dá é a passagem do conceptual para o linguístico:

[...] trata-se, aqui, da terminologização lato sensu, ou seja, uma criação ex-nihilo, que terá graus diferentes de motivação, mas que não resulta da transposição de um universo de discurso para outro e, sim, da instauração de uma nova grandeza sígnica - numa combinatória inédita, no caso do processo fonológico ou sintagmático - e de uma função metassemiótica - no caso do processo semântico. (BARBOSA, 2007, p. 438)

Neste trabalho, admitiremos a terminologização como arquiconceito e arquitermo em que há a neutralização da oposição entre terminologização lato sensu (passagem do conceptual para o linguístico), da terminologização stricto sensu (transformação de um vocábulo em termo) e a metaterminologização (instauração de um termo a partir de outro termo). Consideramos que nos autoriza essa neutralização das diferenças a própria asserção de Barbosa (2007, p. 438-439):

A rigor, este processo - o da terminologização lato sensu - subjaz a todos os anteriormente apresentados, visto que, em estrutura profunda, o ponto de partida é sempre o nível conceptual (PAIS [...]). Diferem quanto aos percursos realizados pela grandeza-termo e quanto ao modo como é engendrada: fonológico, semântico, sintagmático ou alogenético (GUILBERT [...]) 
Assim, será mencionado apenas o termo "terminologização”, como termo geral, como macroprocesso de transposição do conceptual para o linguístico no percurso do conceito para o termo.

\section{Teoria Comunicativa da Terminologia e Teoria Sociocognitiva da Terminologia}

Utilizamos algumas abordagens teórico-metodológicas da Teoria Comunicativa da Terminologia e da Teoria Sociocognitiva da Terminologia, principalmente no que concerne à: valorização dos estudos semânticos, pragmáticos e morfossintáticos, sob um enfoque descritivista e não prescritivista (como os fundamentos da TGT ou Teoria geral da Terminologia de Wüster); concepção de termo como unidade de função comunicativa e discursiva; valorização de aspectos sociológicos e históricos que influenciam a língua e as linguagens; funções comunicativa, cognitiva e discursiva dos termos, além da motivação terminológica; valorização do estudo dos discursos das línguas de especialidade, com ênfase em sua identidade e sua autonomia; estudo da difusão do conhecimento científico (BARBOSA, 2007; CABRÉ, 1993; 1999; DEMAI, 2014; TEMMERMAN, 2001).

Maria Teresa Cabré e colaboradores fundaram a chamada Teoria Comunicativa da Terminologia (TCT), que, como a própria denominação sinaliza, assume o estudo terminológico de um ponto de vista comunicativo, o que pressupõe a análise das variáveis pragmáticas que direcionam a formação e a utilização das terminologias.

A Teoria Sociocognitiva da Terminologia (TST) foi proposta por Temmerman já no final da década de 1990 e início dos anos 2000, em Bruxelas. A TCT e a TST trazem diversas críticas à TGT de Wüster e seus seguidores. A TST propõe ir além dos parâmetros atuais (tradicionais) de Semasiologia/Onomasiologia: propõe um papel comunicativo e cognitivo para a Terminologia, considerando o conhecimento linguístico em seu âmbito pré-linguístico e mental.

A seguir, resumimos alguns aspectos da TST (TEMMERMAN, 2001, p. 74-91):

- a TST parte de unidades de conhecimento, de acordo com a concepção de que as pessoas entendem o mundo por meio de frames cognitivos ou modelos;

- os conceitos são tidos como categorias mais abrangentes, que possuem estruturas prototípicas. 
Como convergência entre as propostas da Teoria Comunicativa da Terminologia (TCT) e da Teoria Sociocognitiva da Terminologia (TST), salientamos as proposições de que termo é um signo linguístico, que representa um conhecimento especializado com as faces significado e significante intimamente ligadas, em uma relação de interdependência e complementaridade.

\section{O corpus: coleta e sistematização de dados terminológicos}

\section{O corpus de análise deste artigo}

O corpus de análise, como o concebemos neste trabalho, é o conjunto de termos extraídos de diversos textos representativos da área para estudo, organizado por nós, pertencente a uma sincronia de 16 anos e que perfaz cerca de 100 termos. Trata-se de uma amostragem de corpus, extraído de fontes como documentos legais (legislações educacionais federais e estaduais, trabalhos acadêmicos, livros de pesquisadores independentes).

As instituições pesquisadas, cujos textos serviram à extração de termos, foram: Centro Estadual de Educação Tecnológica Paula Souza (estado de São Paulo), Ministério da Educação e Ministério do Trabalho e Emprego (governo federal do Brasil), além do trabalho de pesquisadores autônomos.

Como critérios para a seleção da amostragem, foram coletados termos neológicos (posteriores a 2000, em forma e/ou em significado) diretamente ligados ao "novo" paradigma da educação profissional técnica de nível médio por competências instauração do currículo por competências em oposição ao currículo por conteúdos isolados ou puramente enciclopédicos.

Para início da pesquisa, foi estruturado o corpus de partida ou parâmetro, que é o conjunto de textos que servem à extração de termos (e respectivos conceitos), com datação não predefinida, que tratam com propriedade da área-tema, por serem textos de autores e instituições representativos.

Esse conjunto de textos mais geral, cuja recolha e sistematização foi o primeiro procedimento metodológico, foi organizado, filtrado e serviu de ponto inicial da pesquisa, 
em seu estado bruto; foi mantido como parâmetro para comparações e para extração das palavras-chave em etapas posteriores da pesquisa.

Foi estruturado também um corpus de exclusão específico, ou seja, um conjunto de textos mais antigos da área (paradigma dos anos de 1970, que perdurou nas décadas de 1980 e de 1990), representando o paradigma imediatamente anterior ao Currículo por Competências em Educação Profissional Técnica de Nível Médio. Os termos encontrados no corpus de exclusão são excluídos (como o próprio nome diz) do corpus de análise neológico.

Como critérios de inclusão de termos, foram selecionadas unidades terminológicas de acordo com uma combinatória de critérios - ou seja, os termos selecionados atenderam a todos os quesitos:

- $\quad$ frequência (ocorreram duas ou mais vezes no corpus);

- $\quad$ representatividade conceitual (são termos que representam conceitos da área-tema) e

- $\quad$ caráter neológico (não ocorrem no corpus de exclusão).

Dessa maneira, foram excluídos os termos não neológicos (ocorrem no corpus de exclusão), não representativos da área, que ocorreram menos de duas vezes na totalidade do corpus e que ocorreram em apenas uma obra do corpus.

Selecionamos também para nosso corpus de análise final itens de caráter enciclopédico (nomes de instituições, programas do governo, tipos de escolas, tipos de cursos, entre outros), por julgarmos que esses elementos são indispensáveis para a configuração conceitual-terminológica da área.

Como critérios de exclusão, foram descartados os textos que não apresentaram termos neológicos e que não apresentaram termos representativos da área.

O corpus pode ser enquadrado na tipologia de obra técnico-científica/legal, prestando-se também às funções pedagógica e de divulgação. Para a identificação e extração de termos propriamente ditas, utilizamos uma metodologia híbrida, na qual foram aliadas a análise humana e ferramentas informatizadas.

Os termos foram selecionados após leitura de todo o corpus e extração semiautomatizada de termos, considerando que nem todos os textos estão disponíveis em formato eletrônico. 
Foram verificadas e validadas as unidades terminológicas coletadas manualmente com a utilização do software WordSmith Tools, um software de análise lexical desenvolvido por Mike Scott, da Universidade de Liverpool, e publicado pela Oxford University Press (SCOTT).

Utilizamos as três ferramentas básicas do WordSmith Tools: WordList (para elaboração de listas de termos); KeyWords (para extração de termos-chave ou palavraschave) e Concord (para extração de concordâncias, expressões ou, ainda, termos sintagmáticos).

A ferramenta WordList gerou uma lista de palavras, por ordem alfabética e também por frequência, apresentando inclusive um tratamento estatístico das informações. São exemplos da sequência de nossa Wordlist: “Área profissional”; “Atitudes”; “Atribuições”; “Atribuições e atividades”; “Atualização curricular”; “Avaliação por competências”; “Avaliação por conteúdos”; "Bases tecnológicas”; “Catálogo Nacional de Cursos Técnicos”; “CBO”; “Certificação intermediária”.

KeyWords é a ferramenta que gera a lista de palavras-chave a partir das listas criadas pela ferramenta WordList; são selecionadas as palavras-chave, que apresentam uma frequência diferenciada (maior) em relação aos demais itens lexicais, possibilitando afirmar que são palavras-chave dos textos do corpus de análise.

Como demonstração, apresentamos uma parte da lista das KeyWords geradas para nossa análise lexical: “Competências”; “Competências atitudinais”; “Competências gerais"; “Competências laborais”; “Competências pessoais”; “Competências profissionais”; “Competências profissionais específicas”; “Competências profissionais gerais”.

Concord é a ferramenta que gera listas de ocorrências e contextos das palavras buscadas. A ferramenta pode ser utilizada isoladamente ou em conjunto com as duas outras ferramentas já citadas, WordList e KeyWords.

Como ilustração, apresentamos uma parte das listas Concord geradas para nossa análise lexical, no que se refere aos sintagmas preposicionados "da educação profissional" ou "em educação profissional”: "Currículo da educação profissional”; "Currículo da educação profissional técnica”; “Currículo da educação profissional técnica de nível médio”; “Currículo em educação profissional por competências”. 
Para o estudo de termos sintagmáticos, formados por mais de um item lexical, a ferramenta Concord é essencial, pois busca os contextos (pelo menos a frase em que o termo ocorre), permitindo, assim, identificar os determinantes adjetivais ou adjetivos simples, a exemplo de "profissional” em “competência profissional” ou ainda os determinantes em forma de sintagma preposicionado, com valor adjetival, a exemplo de “da educação profissional” em “Currículo da educação profissional”.

Os termos encontrados não foram modificados e sim extraídos tal e qual sua ocorrência no corpus. A organização propriamente dita de termos e de suas características foi feita em planilhas eletrônicas, obtidas a partir da utilização das ferramentas básicas do WordSmith Tools.

Em síntese, podemos elencar os procedimentos metodológicos:

- organização do corpus de partida ou parâmetro, ou seja: um conjunto de textos mais gerais, um corpus bruto, que, a partir dos critérios e objetivos estabelecidos, é filtrado e recortado para dar origem ao corpus de análise (conjunto de termos para análise conceptual-terminológica);

- organização do corpus de exclusão específico, ou seja: o conjunto de textos mais antigos da área, que servirá para pôr em prática o critério da neologicidade: os termos que aparecem nesse corpus de exclusão não serão incluídos no corpus de análise, que é o conjunto formado apenas pelos termos mais novos ou neológicos;

- leitura e coleta manual de termos dos corpora de partida ou parâmetro e do corpus de exclusão específico;

- tratamento inicial (manual) do corpus de partida ou corpus parâmetro: exclusão dos termos considerados não neológicos, conforme a datação dos textos em que são encontrados; exclusão dos termos não representativos da área-tema; exclusão de termos que ocorreram menos de duas vezes na totalidade do corpus; exclusão de termos que ocorreram em apenas uma obra (texto) do corpus.

- listagem dos termos (e respectivos textos de origem) que não foram excluídos no tratamento inicial do corpus de partida ou corpus parâmetro, que dão origem à primeira versão do corpus de análise.

- tratamento informatizado da primeira versão do corpus de partida ou corpus parâmetro: extração automatizada da lista de palavras (Worlist) dos textos de origem, das palavras ou termos-chave (KeyWords) e das concordâncias (Concord) para verificação, 
complementação e eventual correção da lista de termos (corpus de análise) coletada manualmente.

- organização da versão final da lista de termos (e respectivos textos de origem) para análise, após os procedimentos de extração manual e de extração automatizada de termos, combinados em uma metodologia híbrida de estudo de corpus.

- elaboração de planilha(s) no programa Microsoft Excel, com os termos e respectivas características que se quer estudar, a exemplo de: estrutura morfossintática (incluindo especificações de formação simples, composta, sintagmática, siglada ou acronímica), ocorrência de sinônimos, antônimos, variantes em relação ao termo preferencial, tipo de neologia que caracteriza a formação do termo, gênero e número do substantivo, entre outras características, a serem determinadas pelo pesquisador, conforme seus objetivos. Em nossa pesquisa, denominamos isso de "Planilha do corpus de análise final” - ela subsidia a exposição, a análise e a discussão dos termos e dos processos de terminologização subjacentes, ao lado do referencial teórico, conforme nossos propósitos neste trabalho. Ressaltamos que nem todas as características dos termos sistematizadas serão pertinentes ou representativas para a análise. Logo, essa planilha é um instrumento para a análise, não se confundindo com a análise propriamente dita, que é uma função e um produto de responsabilidade do pesquisador, a partir da mobilização dos dados coletados e organizados, do patamar cognitivo alcançado com a leitura de todos os textos dos corpora e do referencial teórico.

A seguir, exemplificamos com um extrato da "Planilha do corpus de análise final”, por nós organizada: 
Quadro 1: Planilha do corpus de análise final

\begin{tabular}{|c|c|c|c|c|c|}
\hline Termo & $\begin{array}{c}\text { Estrutura } \\
\text { morfossintática }\end{array}$ & $\begin{array}{c}\text { Pref - termo } \\
\text { preferencial } \\
\text { Sin - } \\
\text { sinônimo } \\
\text { Ant - } \\
\text { antônimo } \\
\text { Var - } \\
\text { Variante } \\
\text { fonológica } \\
\text { ou gráfica } \\
\end{array}$ & $\begin{array}{l}\text { Gênero e } \\
\text { número do } \\
\text { substantivo }\end{array}$ & $\begin{array}{c}\text { Termos } \\
\text { simples } \\
\text { (TS), } \\
\text { compostos } \\
\text { (TC), } \\
\text { complexos } \\
\text { (TX) ou } \\
\text { siglas ou } \\
\text { acrônimos }\end{array}$ & $\begin{array}{l}\text { Tipo de neologia - } \\
\text { predominante } \\
1 \text { - fonológica } \\
2 \text { - morfossintática } \\
3 \text { - semântica } \\
4 \text { - por empréstimo } \\
\text { interno }\end{array}$ \\
\hline Área de atividades & subs + prep + subs & pref & sf sing & $\mathrm{TX}$ & 2 \\
\hline Área profissional & subs + adj & pref & sf sing & $\mathrm{TX}$ & 2 \\
\hline Atitudes & subs & pref & sf pl & TS & 3 \\
\hline Atribuições & subs & pref & sf pl & TS & 3 \\
\hline $\begin{array}{l}\text { Atribuições e } \\
\text { atividades }\end{array}$ & subs + conj + subs & pref & sf pl & $\mathrm{TX}$ & 2 \\
\hline $\begin{array}{l}\text { Atualização } \\
\text { curricular }\end{array}$ & subs + adj & pref & sf sing & $\mathrm{TX}$ & 2 \\
\hline $\begin{array}{l}\text { Avaliação por } \\
\text { competências }\end{array}$ & subs + prep + subs & pref & sf sing & $\mathrm{TX}$ & 2 \\
\hline $\begin{array}{l}\text { Avaliação por } \\
\text { conteúdos }\end{array}$ & subs + prep + subs & pref & sf sing & TX & 2 \\
\hline Bases tecnológicas & subs + adj & pref & sf pl & TX & 2 \\
\hline
\end{tabular}

Fonte: Elaboração própria

Essa planilha foi utilizada, por exemplo, para filtrar as estruturas morfossintáticas mais frequentes, como "substantivo + preposição + substantivo", e "substantivo + adjetivo”. A planilha foi utilizada também para registro e extração de dados como a quantidade (e quais são ocorrências) de termos simples, de termos complexos (ou compostos sintagmáticos), quais são as formas preferenciais, sinonímicas, antonímicas ou variantes e qual é o tipo de neologia predominante (entre fonológica, morfossintática, semântica, por empréstimo - interno e externo), além de características de gênero (feminino e masculino) e de número (singular e plural) dos substantivos.

Para ocorrências diferenciadas, é necessário triar e registrar outras características dos termos - para o estudo de termos formados por verbos, por exemplo, estudamos fatores como número, pessoa, modo, tempo, aspecto, voz, formas nominais. Uma ocorrência é: saber fazer (verbo + verbo, infinitivo + infinitivo). Detivemos mais tempo na análise de substantivos, pelo fato de ocorrerem mais, mas verbos e adjetivos também têm alta relevância e espaço nos estudos conceptuais e terminológicos. 


\section{Análise e discussão}

A ação, única atividade que ocorre diretamente entre os homens, sem a mediação das coisas ou da matéria, corresponde à condição humana da pluralidade, ao fato de que os homens, e não o Homem, vivem na Terra e habitam o mundo. Embora todos os aspectos da condição humana tenham alguma relação com a política, essa pluralidade é especificamente a condição - não apenas a conditio sine qua non, mas a conditio per quam - de toda vida política [...]

(Hannah Arendt, A condição humana)

\section{O engendramento dos conceitos contrários “organização curricular por} competências” e “organização curricular por conteúdos isolados”

De forma esquemática, representa-se a tensão entre os conceitos contrários “Organização curricular por competências” e “Organização curricular por conteúdos isolados” no Currículo da Educação Profissional Técnica de Nível Médio:

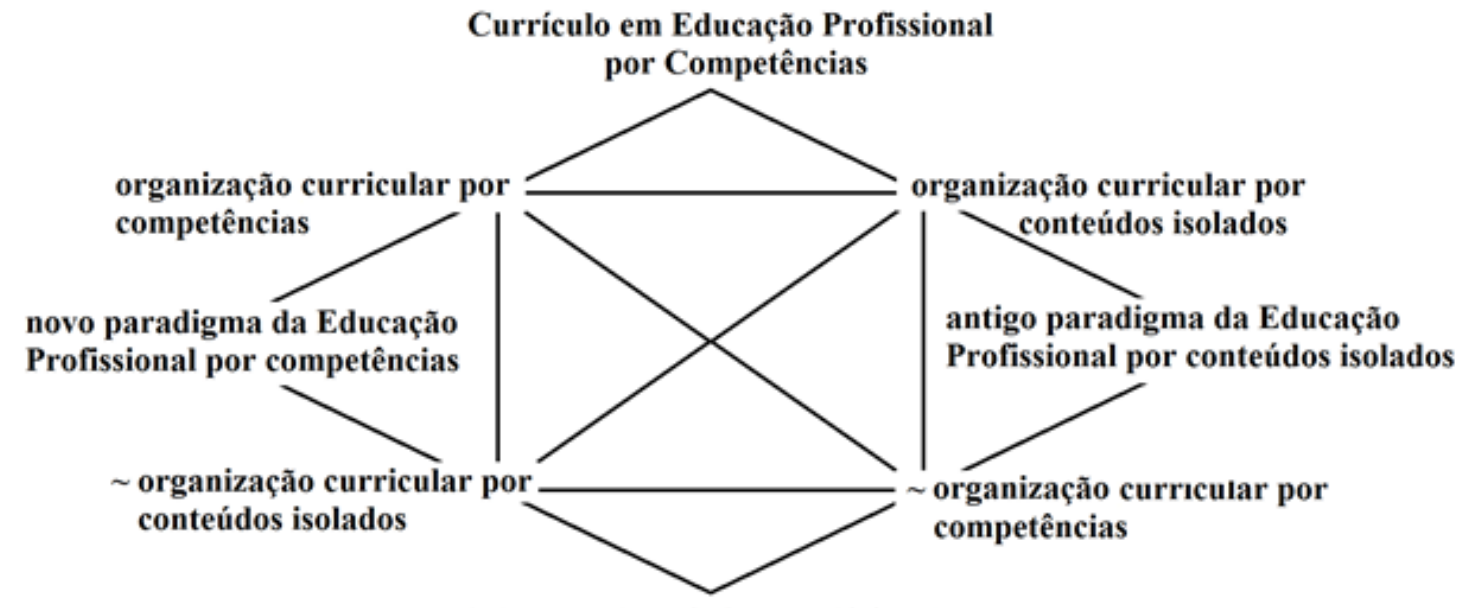

Educação Brasileira Tradicional

Figura 1: Octógono semiótico - Currículo em Educação Profissional por competências na Educação brasileira tradicional - contrários e contraditórios

Fonte: Elaboração própria

No octógono semiótico da Figura 1, podem ser verificadas as relações de significação em que há associação e também oposição de conceitos. Do lado esquerdo, a 
“organização curricular por competências” e a “ organização curricular por conteúdos isolados” (= não organização curricular por conteúdos isolados, ou seja, o que contradiz esse conceito) leva a um novo paradigma da Educação Profissional por competências; do lado direito, a “organização curricular por conteúdos isolados” e a negação da “organização curricular por competências” leva à significação do antigo paradigma da Educação Profissional por conteúdos puramente enciclopédicos ou “isolados”. Essa figura representa os contrários, ou seja, a “organização curricular por competências” e a “organização curricular por conteúdos isolados”, no universo da organização curricular, na Educação Brasileira Tradicional.

Propõe-se na “organização curricular por competências profissionais” que se contrarie o paradigma de currículo organizado por conteúdos isolados, sem ligação a objetivos educacionais bem definidos.

Em 2000, com a publicação dos Referenciais Curriculares Nacionais da Educação Profissional de Nível Técnico, pelo Ministério da Educação (MEC, 2000), houve uma explícita intenção de romper o paradigma de Currículo em Educação Profissional Técnica focado em "conteúdos a serem ensinados”, com vistas a um novo “paradigma em implantação”, com “foco nas competências a serem desenvolvidas/nos saberes (“saber”, “saber fazer” e “saber ser”) a serem construídos”.

Nessa “nova” perspectiva (que já completou 16 anos), o currículo não significava mais um fim, um ideal a ser alcançado, como o simples rol de conteúdos a serem ensinados e aprendidos, mas sim "um conjunto de situações-meio, pedagogicamente concebidas e organizadas para promover aprendizagens profissionais significativas” (MEC, 2000, p. 11), conforme a figura a seguir: 


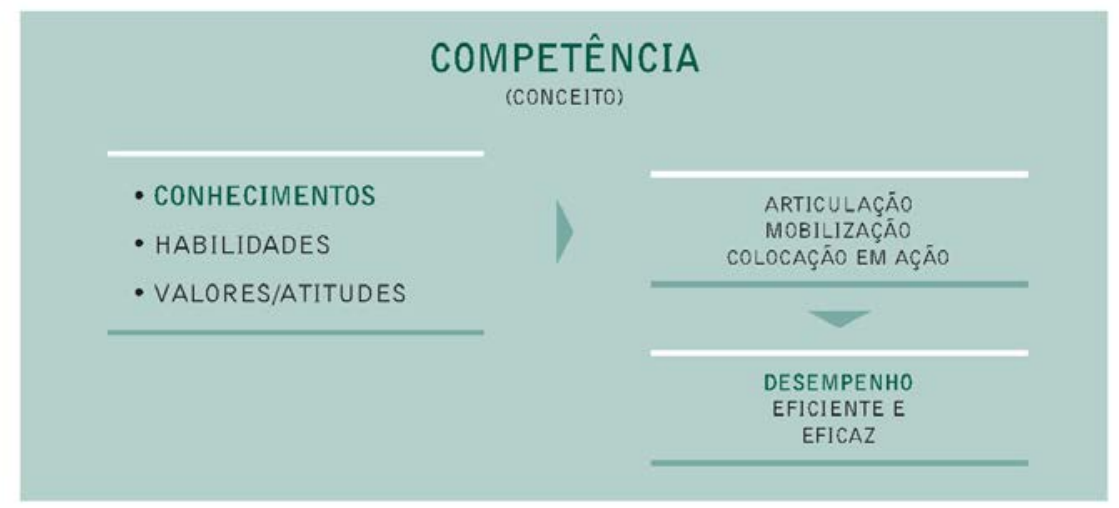

0 quadro a seguir identifica os pontos essenciais da mudança de paradigma que está no núcleo da reforma da educação, particularmente da educaçắo profissional.

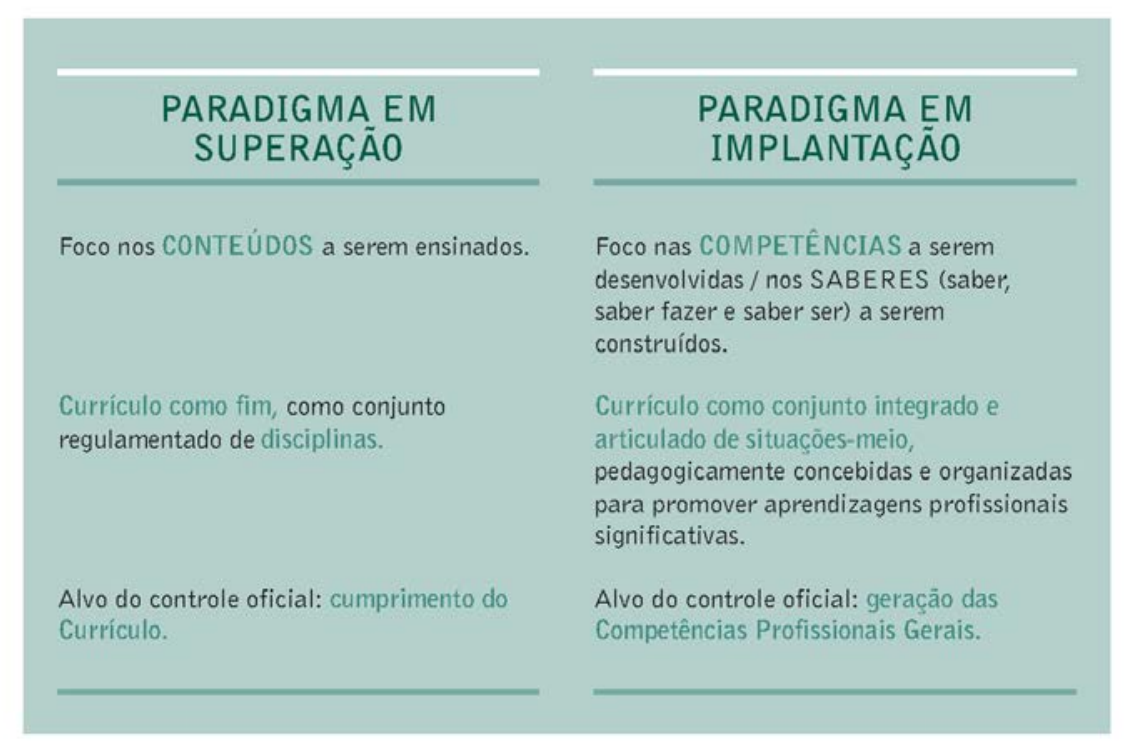

Figura 2: Competência (conceito), Paradigma em Superação, Paradigma em Implantação Fonte: MEC (2000, p. 11)

Na leitura da Figura 2, pode-se constatar a ideologia subjacente ao planejamento, à execução e à gestão curricular: um projeto de reforma educacional que visou atribuir à área de Currículo em Educação Profissional Técnica uma função sociocultural diferenciada, o domínio e a evidenciação de competências profissionais.

Na Figura 3, logo a seguir, verifica-se o engendramento da matriz de referência para o currículo em EPT na forma em que o reconhecemos até hoje nas instituições de ensino. Nota-se a tríade “competências”, "habilidades” e "bases tecnológicas” como categorias fundamentais na concepção e na representação do currículo: 


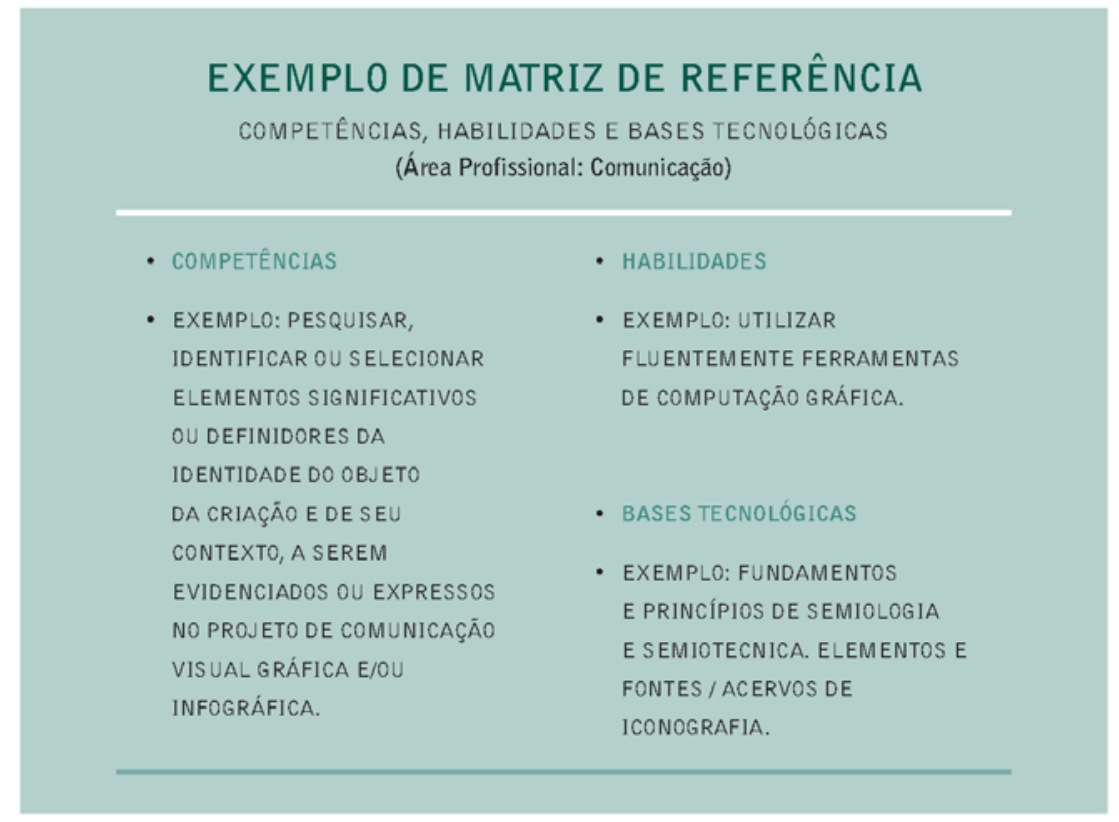

Para cada subfunção componente do processo produtivo de uma área profissional, foram também identificadas e serão alvo de publicação complementar bases científicas - conceitos e princípios das ciências da natureza, da matemática e das ciências humanas, que fundamentam as tecnologias e as opçōes estéticas, políticas e éticas da atividade profissional em questão - e bases instrumentais . domínio de linguagens e códigos que permitem "leitura" do mundo e comunicação com ele e de habilidades mentais, psicomotoras e de relação humana, gerais e básicas.

Estas bases permitem a percepção clara dos requisitos de entrada para a apropriação das bases tecnológicas e para o desenvolvimento das competências e habilidades envolvidas em cada subfunção integrante do processo de produção na área profissional. Assim, quadros de bases científicas e instrumentais serão posteriormente publicados para oferecer referências para que se estabeleçam as ligaçōes específicas entre os currículos da educação básica e os da educação profissional na área objetivada, subsidiando processos seletivos ou de caracterização de candidatos e a organizaçăo de possíveis módulos curriculares destinados ao nivelamento ou à recuperação dessas bases prévias.

Figura 3: Exemplo de matriz de referência (Competências, habilidades e bases tecnológicas)

Fonte: MEC (2000, p. 27)

Por quase uma década, a Educação Profissional Técnica de Nível Médio ficou impetrada, legalmente e na práxis decorrente da tríade comentada (“competências”, “habilidades” e "bases tecnológicas”), com a organização a partir de taxes ou categorias denominadas "áreas profissionais".

Em 2008, com as disposições do Conselho Nacional de Educação, pela Câmara da Educação Básica, previstas na Resolução CNE/CEB n. 3, de 9 de julho, o paradigma da Educação Profissional Técnica de Nível Médio foi remodelado, de uma organização 
de cursos técnicos em núcleos categorizadores denominados “áreas profissionais” para novas classes, mais abrangentes: “eixos tecnológicos” (MEC, 2008a).

O Parecer CNE/CEB n. 11/2008 resgata o histórico da mudança de paradigma de organização curricular, de áreas profissionais para eixos tecnológicos:

As Diretrizes Curriculares Nacionais para a Educação Profissional Técnica de Nível Médio foram definidas pela Resolução CNE/CEB n ${ }^{\circ}$ 4/99, com base no Parecer CNE/CEB n ${ }^{0}$ 16/99. Com a edição do Decreto 5.154/2004, o conjunto dessas Diretrizes Curriculares Nacionais foi atualizado pelo Parecer CNE/CEB n 39/2004, que deu origem à Resolução CNE/CEB n ${ }^{\circ} 1 / 2005$. Essas Diretrizes organizavam a oferta da Educação Profissional por áreas profissionais, isto é, segundo a lógica de organização dos setores produtivos. O Ministério da Educação está propondo, nesta oportunidade, uma nova orientação para organizar a oferta da Educação Profissional Técnica de Nível Médio, similar à orientação já seguida na definição do Catálogo Nacional de Cursos Superiores de Tecnologia, objeto do Parecer CNE/CES nº 277/2006. O MEC está propondo uma nova organização por Eixos Tecnológicos, isto é, segundo a lógica do conhecimento e da inovação tecnológica [...] O Catálogo, a ser instituído por força de Portaria Ministerial, contemplará as seguintes disposições por eixo tecnológico: nomes das habilitações profissionais ou cursos técnicos de nível médio e respectivos descritores e carga horária, possibilidades de temas a serem abordados, possibilidades de atuação profissional e infraestrutura recomendada. (MEC, 2008b, p. 8-9)

Pode-se notar, no referencial exposto, o engendramento de outro conceito, “a Educação Profissional Técnica de Nível Médio fundamentada na lógica do conhecimento e da inovação”, não necessariamente ou explicitamente contrária ou contraditória em relação à "Educação Profissional Técnica de Nível Médio fundamentada na lógica das competências profissionais”.

O paradigma da organização curricular a partir de 2008 tornou-se mais neutro, menos marcado, priorizando uma organização curricular por temas, não por competências, nem por conteúdos isolados. A partir de nossa análise de corpus, constatamos que, na prática das instituições, a organização curricular por competências não perdeu força em sua trajetória, continuando a ser a mais representativa entre as principais instituições de ensino técnico, públicas e também particulares.

No percurso conceptual-terminológico de Currículo por competências na Educação Profissional Brasileira, nos 16 anos que compõem a sincronia estudada, foram terminologizados (colocados em forma de termo) os seguintes conceitos-chave: 
"currículo por competências”; “competências profissionais”; "habilidades profissionais”; "bases tecnológicas”; “perfil profissional”; “atribuições e atividades profissionais”; “função produtiva”, além de conceitos subordinados.

Foi engendrado o arquiconceito “organização curricular por competências” e também seu contrário, “organização curricular por conteúdos isolados”, com a contraposição dos paradigmas: o "novo”, da Educação Profissional por Competências e o “antigo”, da Educação Profissional por Conteúdos Isolados.

\section{Processos de terminologização: a configuração de alguns termos neológicos da área de Currículo por Competências em Educação Profissional Técnica de Nível Médio}

Nesta seção, apresentamos uma análise dos processos de terminologização que caracterizam alguns dos termos neológicos mais representativos da área, a exemplo de: “currículo por competências”; “competências profissionais”; "bases tecnológicas”, além dos próprios arquitermos/arquiconceitos contrários “organização curricular por competências” e “organização curricular por conteúdos isolados”.

É a neologia morfossintática/sintagmática, a que se dá pela formação de um novo signo a partir da combinação de vários signos distintos já existentes na língua, a que mais se destaca, quantitativamente e qualitativamente, na formação dos termos que compõem nosso corpus de análise.

Outros tipos de neologia encontrados em caráter de combinação ou de complementaridade ao processo sintagmático: neologia semântica (novos significados atribuídos a signos já existentes ou a novas combinatórias sintagmáticas), neologia por empréstimo interno (de outras áreas do conhecimento e da língua geral). Não nos aprofundamos no estudo da neologia semântica como processo principal neste trabalho e sim como processo complementar, em combinatória com o processo morfossintático de terminologização.

Para fins metodológicos, na extração dos termos e organização na "Planilha do corpus de análise final”, diferenciamos termos simples (TS), termos compostos (TC) e termos complexos (TX).

Escolhemos a denominação "termos simples” neste trabalho, os quais podem também ser denominados “termos lexemáticos” ou “termos-palavras”. Utilizaremos 
também a denominação “termos complexos”, a qual concorre, muitas vezes, com “termos sintagmáticos”, “termos-sintagmas” ou “sintagmas terminológicos” (BARROS, 2004, p. 101).

Neste artigo, concebemos “termos compostos propriamente ditos” como aqueles constituídos por mais de um elemento vocabular, não separáveis e não intercambiáveis, formando um sentido único apenas com a formação cristalizada, já de consenso na comunidade sócio-linguístico-cultural (ligados ou não por hífen). Esses termos não são representativos em nosso corpus de análise. Os termos neológicos, por seu próprio caráter de inovação ou novidade, ainda não usufruem de consenso ou já se constituem em formas “cristalizadas” ou “consagradas”. Seus significados (e sua própria existência) são desconhecidos, totalmente ou em parte, pela maioria da comunidade sócio-linguísticocultural.

Os termos complexos, também formados por mais de um elemento vocabular, não ligados por hífen, em diferentes gradações de lexicalização (terminologização) são a maioria em nosso corpus.

Destacamos, em forma de gráfico, as estruturas morfossintáticas mais recorrentes:

Gráfico 1: Estruturas morfossintáticas mais representativas - terminologia do Currículo por Competências em Educação Profissional Técnica de Nível Médio

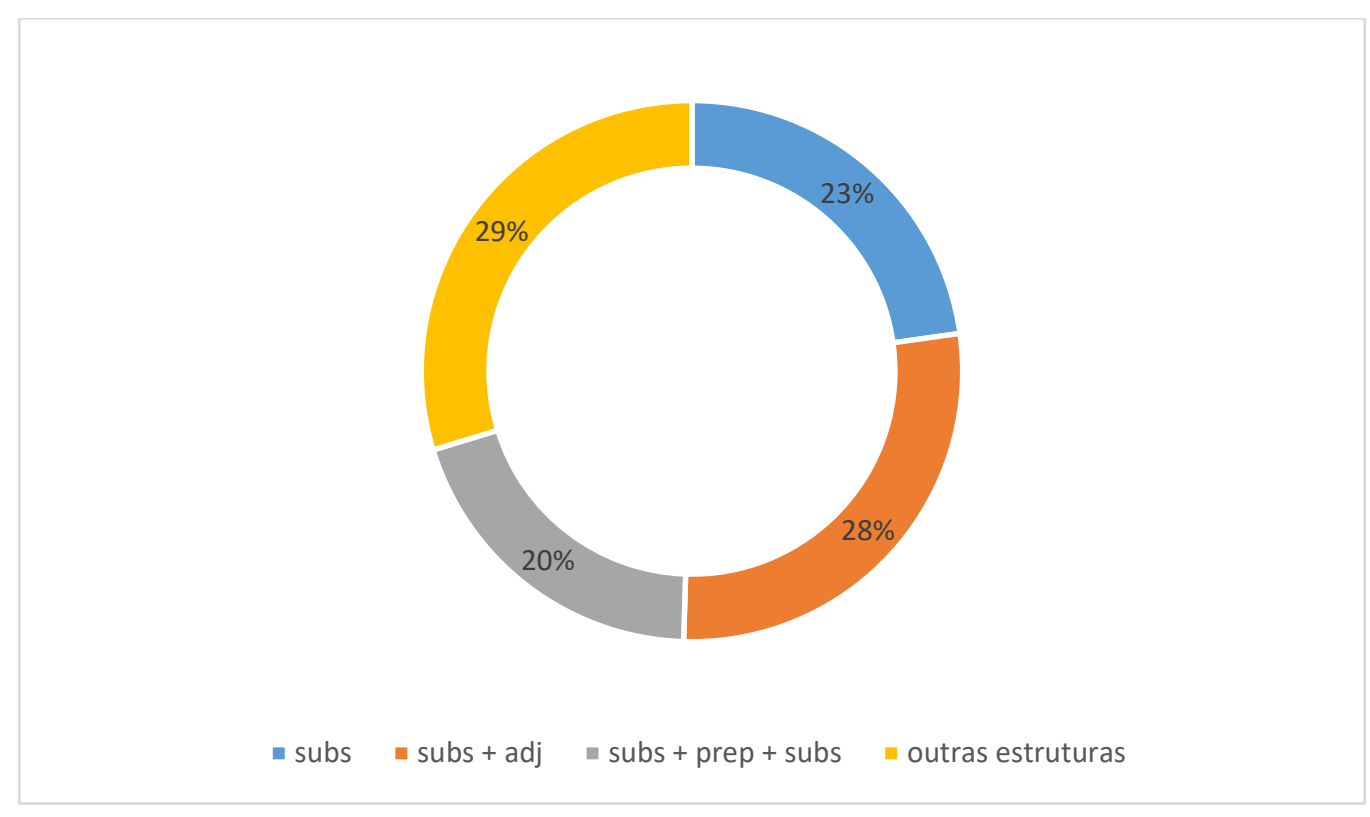

Fonte: Elaboração própria. 
Quanto aos termos complexos (formados por sintagmação), a estrutura morfossintática mais representativa é substantivo + adjetivo, com 28\% das ocorrências, seguida da estrutura substantivo + preposição + substantivo, com 20\%.

Outras formas menos representativas percentualmente foram agrupadas na categoria "outras estruturas", a exemplo de: substantivo + adjetivo + adjetivo (3 ocorrências); substantivo + adjetivo + preposição + substantivo (3 ocorrências); substantivo + conjunção + substantivo (2 ocorrências); substantivo + preposição + adjetivo + substantivo (3 ocorrências).

Para novos conceitos, os termos devem ser novos, neológicos, e, para a área de Currículo por Competências, à semelhança de outras áreas, existe a necessidade de especificação de um termo genérico, com a expansão sintagmática cada vez mais e mais presente nas terminologias. Esse é o processo mais produtivo na neologia da área em estudo: não a criação de uma nova sequência fonológica, não a atribuição de novos significados a significantes já existentes, de modo isolado, mas sim novas combinatórias de elementos lexicais já existentes, com a atribuição de significado totalmente novo e que não se confunde com o significado isolado das partes, mas que é um significado composicional, que só existe na e pela composição, mais especificamente pela composição sintagmática.

Todavia, não podemos desprezar os termos simples, formados por uma só lexia, surpreendentemente representativos no corpus deste trabalho (20\%); a ocorrência de termos simples deve ser sublinhada, pois, nas terminologias técnicas e científicas, a sintagmação é um processo muito frequente - a determinação dos substantivos faz-se quase que obrigatória, para dar conta das especificidades dos novos conceitos, dos mais diversos campos do saber.

A existência de termos simples nos leva à análise da função categorial e prototípica dos conceitos, conforme os fundamentos da Teoria Sociocognitiva da Terminologia (TEMMERMANN, 2001). No caso dos termos simples, o processo neológico dá-se exclusivamente no campo semântico: a uma forma já existente, atribuise novo conteúdo; seu significado é apreendido exclusivamente em contexto, visto que termos neológicos não constam de dicionários de língua geral e nem em contextos definitórios ou eventuais glossários de textos técnicos mais antigos da área. 
A título de exemplificação, apresentamos os termos sintagmáticos, em nosso corpus de análise:

(1) Com a estrutura morfossintática predominante, substantivo + adjetivo: “Competências atitudinais”; “Competências laborais”; “Competências gerais”; “Competências pessoais”; “Competências profissionais”; “bases tecnológicas”; “componente curricular”; “matriz curricular”; “organização curricular”; “planejamento curricular”; "reformulação curricular”, entre outros.

O determinante adjetival é imprescindível para a terminologização, como ocorre com o conceito “competências”, genérico, que se constitui em uma categoria - com a determinação adjetival, há a formação de termos mais específicos, como "competências laborais”, “competências atitudinais”, entre outros.

(2) Com a segunda estrutura morfossintática mais representativa: substantivo + preposição + substantivo: “área de atividades”; “avaliação por competências”; “avaliação por conteúdos”; “currículo por competências”; “currículo em parceria”; "laboratório de currículo”; “área de atividades”; “matriz de referência”; “descrição de cargos”; “possibilidades de temas”; “solução de problemas”; “possibilidades de atuação”; "síntese de competências”; “perfil de competências”, entre outros. O determinante em forma de sintagma preposicionado, de valor adjetival, especifica os termos mais genéricos, formando outros termos. É a produtividade da neologia sintagmática que se verifica também aqui, como em todos os termos compostos por sintagmação.

Exemplificamos também os termos simples, formados por uma só lexia: “competências”, “atitudes”, “habilidades”, “atividades”, “currículo”, “eixo”, “funções”. Esses termos simples são arquitermos, ou seja, termos mais abrangentes, com função categorial, em cuja estrutura semântico-pragmática se neutralizam as oposições mais específicas, fator que os conduz ao estatuto de classe.

Segundo a Teoria Sociocognitiva da Terminologia, os conceitos têm a função de modelo e de protótipo. A cognição se daria com essas representações mais abrangentes. Os termos simples, em nosso corpus, representam categorias, enquanto os termos sintagmáticos compostos a partir dessas categorias são seus elementos. Dessa forma, as classes são mais genéricas, menos específicas, justamente por haver a neutralização das diferenças (arquiconceito) para sua constituição, sem o que não seria possível a inclusão de elementos mais específicos, que contenham os traços semânticos arquiconceituais e os 
seus traços específicos, que os distinguem como indivíduos dentro de uma mesma classe, correlacionados pelo fato mesmo de pertencerem a uma classe, mas não confundíveis em sua individualidade. Os termos compostos sintagmaticamente são os elementos dessas classes (que são os termos simples).

O subprocesso de terminologia morfossintática garante a pertença dos elementos à classe ou protótipo ou arquiconceito. Assim, “competências” seria uma categoria ou arquiconceito, a que estariam relacionados os elementos: “competências profissionais”; “competências atitudinais”; “competências laborais”; “competências gerais”; “competências gerais”; “competências específicas”.

Dessa feita, as relações entre o eixo paradigmático e o eixo sintagmático são estabelecidas, pois, dentre as opções randômicas e virtualidades (paradigma potencial de classe), são escolhidos e dispostos materialmente, em forma de sequência sintagmática organizada, do menos para o mais fixo ou cristalizado (terminologizado), os elementos (termos compostos sintagmáticos) no continuum linguístico, observadas as determinantes extralinguísticas dos discursos que formam o corpus textual (históricas, culturais, sociológicas).

Quanto a esses termos (competências, atitudes, habilidades, atividades, currículo, eixo, funções), observamos também que foram mantidas as características de número dos termos, extraídas em discursos reais que constituem o corpus, ou seja, substantivos no singular ou no plural.

Ressaltamos que também têm representatividade no corpus deste artigo formações ainda mais expandidas à direita:

(3) substantivo + adjetivo + preposição + substantivo + adjetivo + adjetivo + preposição + substantivo + adjetivo: "Referenciais Curriculares da Educação Profissional Técnica de Nível Médio”; “Política Curricular de Educação Profissional Técnica de Nível Médio";

(4) substantivo + preposição + substantivo + preposição + substantivo + preposição + substantivo: "Planejamento do Trabalho de Conclusão de Curso"; "Desenvolvimento do Trabalho de Conclusão de Curso";

(5) substantivo + adjetivo + adjetivo + preposição + artigo + substantivo + adjetivo + adjetivo + preposição + substantivo + adjetivo: "Diretrizes Curriculares Nacionais para a Educação Profissional Técnica de Nível Médio”; 
(6) verbo + verbo: "saber ser”; "saber fazer".

As formações mais expandidas à direita representam a necessidade cada vez maior de especificação dos termos, a propriedade da terminologia de se constituir por categorias mais genéricas, frames ou modelos mentais, que podem ser expandidos e determinados quase que infinitamente, aproveitando-se as capacidades mentais de recuperação de informações e sistematização em conjuntos conceituais e também diferentes estágios ou graus de lexicalização e de terminologização das palavras e/ou dos termos, que estão em constante modificação discursiva e que apresentarão variação em sua forma e/ou em seu conteúdo em diferentes recortes, sincrônicos ou diacrônicos. As formações sigladas e acronímicas justificam-se pelo princípio da economia linguística, que garante a função comunicativa da linguagem e sua eficiência.

Diferenciando os dois tipos, Alves (2001, p. 63) define siglas como "termos formados pelas letras iniciais de um sintagma" e acrônimos como "termos formados pela redução do sintagma sob forma de sílabas, geralmente as iniciais, as quais são pronunciadas como uma palavra autônoma".

Exemplos:

(7) siglas: CNCT (Catálogo Nacional de Cursos Técnicos); DTCC (Desenvolvimento do Trabalho de Conclusão de Curso); PTCC (Planejamento do Trabalho de Conclusão de Curso); CBO (Classificação Brasileira de Ocupações); EPT (Educação Profissional e Tecnológica);

(8) acrônimo: MEC (Ministério da Educação).

Fazemos referência a alguns critérios utilizados para verificação do estatuto de lexicalização dos termos sintagmáticos:

- $\quad$ o grau de integração semântico-sintática indica que não se trata de combinatória eventual e sim de sintagma em vias de lexicalização;

- memorização do sintagma pela comunidade sócio-linguístico-cultural (comprovada por sua utilização recorrente em textos);

- $\quad$ utilização do sintagma em meios de comunicação e/ou em documentos governamentais;

- $\quad$ imprevisibilidade semântica (o significado composicional é diferente e independente do significado isolado dos constituintes do sintagma); 
- $\quad$ possibilidade de substituição do sintagma por termos simples equivalentes (se houver);

- $\quad$ relação do sintagma com a realidade extralinguística, como a designação de objetos de mundo - instituições, documentos, organizações, títulos de obras, entre outros;

- $\quad$ propriedade de o sintagma designar um conceito em particular e de a ele poder ser atribuída uma definição especializada, ou ainda possuir sinônimo(s), quasesinônimos, antônimos ou variantes lexicais ou gráficas;

- $\quad$ impossibilidade de que os elementos do sintagma possam ser comutados, separados, trocados de ordem, determinados isoladamente sem que o significado seja alterado (DEMAI, 2014, p. 281).

Para exemplificar a aplicação desses critérios na verificação do estatuto de lexicalização dos termos sintagmáticos, destacamos o termo:

(9) organização curricular por competências, o qual representa um conceito particular, ou seja, processo ou produto relativo ao planejamento do currículo de cursos técnicos fundamentado no desenvolvimento de competências e na capacidade de solução de problemas no contexto de uma área profissional, não se tratando de combinatória eventual, visto que a combinatória é frequente e recorrente com a mesma forma e significado nos textos da área, de instituições renomadas, do poder legal e também de pesquisadores autônomos. O sintagma pode ser substituído por sinônimos contextuais, como “currículo por competências”; o sintagma é antônimo de “organização curricular por conteúdos isolados”. Os elementos do sintagma não podem ser comutados ou substituídos sem alteração no significado composicional - dessa forma, não seria possível: *organização curricular sem competências ou *competências por organização curricular.

Utilizamos algumas abordagens teórico-metodológicas da Teoria Comunicativa da Terminologia e da Teoria Sociocognitiva da Terminologia, principalmente no que diz respeito à valorização dos estudos semânticos, pragmáticos e morfossintáticos, sob um enfoque descritivista e não prescritivista. Ao analisar os processos de sintagmação, reconhecemos e estudamos a ligação entre morfologia, sintaxe e semântica, a partir de contextos reais de comunicação da área-foco. 
Reconhecemos também a função categorial dos conceitos, na formação de modelos mentais, e algumas das formas de transposição do patamar conceitual para o linguístico, no caso de conceitos que se referem a saberes técnicos e/científicos e o modo como são “colocados” em forma linguística (termo), ou seja, o macroprocesso de terminologização.

A pesquisa é descritivista: não se propõe a modificar, padronizar ou rechaçar as unidades terminológicas encontradas em discurso manifestado e abonadas pelos especialistas e atores sócio-históricos do contexto. Temos a concepção de que termo é uma unidade de função comunicativa, discursiva e cognitiva; os termos sintagmáticos são extraídos de discursos reais, que disciplinam e constroem a área discursivamente, por intermédio de sua terminologia.

\section{Considerações finais}

Os objetivos deste trabalho foram apresentar e analisar os principais aspectos do percurso conceptual-terminológico de “Currículo por competências” na Educação Profissional Técnica de Nível Médio no Brasil. Para a consecução desses objetivos, foram caracterizados e relacionados alguns subprocessos dos macroprocessos “terminologização” e “neologia”.

O certo é que a terminologia da área de Currículo na Educação Profissional Técnica de Nível Médio, com a organização curricular por competências, firmou-se a partir da confirmação e da validação sócio-histórica educacional desse modelo de planejamento curricular em nosso país. Esse modelo não é consensual nem impassível de críticas, já que a própria oscilação legal do Ministério da Educação, a partir de 2008, com um paradigma menos marcado de uma organização curricular por temas (não por competências, não por conteúdos isolados) evidencia essa tensão.

Não obstante uma certa relutância legal (e ideológica), a prática das instituições não se afastaram do paradigma da organização curricular por competências, a despeito da organização curricular por conteúdos isolados e até mesmo da organização curricular por temas (proposta pelo Ministério da Educação em 2008).

A formação dos termos é primordialmente morfossintática, com a predominância de compostos sintagmáticos - entretanto, os termos simples, formados por uma só lexia, 
são frequentes, recorrentes e representativos de conceitos (ou de arquiconceitos) fundamentais para a terminologia em questão. Dessa forma, pode-se correlacionar terminologização e neologia morfossintática. À necessidade de colocação de conceitos técnicos e/ou científicos em forma de termo respondeu-se com o processo de neologia morfossintática pelo qual, a partir da combinatória inédita no eixo sintagmático, dá-se o novo signo terminológico.

A Terminologia, como processo histórico e cultural, político e filosófico, é resultante de subprocessos cognitivos e expressivos de construção de mundo e de realidades; é, em potencial, uma fonte de transmissão do saber, da herança cultural, de indivíduos e de coletividades, a partir do poder de engendrar e de representar os conceitos científicos, técnicos e tecnológicos.

Quanto à área-tema, a Educação Profissional Técnica de Nível Médio, e seu mais novo paradigma de organização curricular por competências, cremos que possui altíssima relevância no atual contexto educacional e social do Brasil, visto que o trabalho é uma das atividades humanas fundamentais para a vita activa (ARENDT, 2014), e uma Educação para o trabalho e para a vida cidadã deve ser valorizada e estudada, a fim de que se torne cada vez mais eficiente em suas práticas e cada vez mais bem construída em seu aparato intelectual subjacente.

A pluralidade (ARENDT, 2014) dos seres humanos, de suas produções, de suas ideias, de seus caminhos (currículos) e das maneiras como estabelecem suas crenças na sociedade é muito rica e constitui-se em vasto campo de pesquisa, inclusive para estudiosos da linguagem.

DEMAI, Fernanda Mello. The route of conceptual-terminological skill-based curriculum in Brazilian professional education. Revista do Gel, v. 14, n. 1, p. 104-132, 2017.

Abstract: School Curriculum (in Professional Technical Education) is defined as a theoretical and methodological scheme that directs the planning and development of professional profiles and skills that meet vocational training objectives, according to the functions and demands of the productive world and of management and production processes. The aim of this study is to demonstrate terminologization aspects in the Curriculum of Professional Technical Education, as well as some relations between terminologization and neology. Creating terms stems from the need of "placing" technical and/or scientific concept into the term, i.e. the terminologization. We propose a study of 
engendering contrary curricular concepts: skills-based curriculum organization and curricular organization by isolated segments in the reconfiguration of the curriculum policy of the High School Professional Technical Education, which took place as from the paradigm of the 2000's in Brazil. We also present an analysis of terminologization processes that characterize some of the most representative neological terms of the area, like: skill-based curriculum; professional skills; technological basis. The corpus consists of legal texts, Brazilian institutional texts and works of independent researchers. We considered some theoretical and methodological approaches about Communicative Theory of Terminology and Sociocognitive Theory of Terminology.

Keywords: Terminology. Neology. Terminologization. Conceptual Analysis. Terminological Description. School Curriculum in Technical Professional Education.

Submetido em: 28/05/2016.

Aceito em: 03/10/2016.

\section{Referências}

ABBAGNANO, N. Dicionário de Filosofia. Tradução coordenada e revista por Alfredo Bosi. Vários tradutores. São Paulo: Mestre Jou, 1970.

ALVES, I. M. Terminologia e Neologia. TRADTerm: Revista do Centro Interdepartamental de Tradução e Terminologia, São Paulo: Humanitas, n. 7, p. 53-70, 2001.

A observação sistemática da neologia lexical: subsídios para o estudo do

léxico. Revista Alfa, São Paulo: ILCSE/ UNESP, v. 50, n. 2, p. 131-144, 2006.

ARAÚJO, A. M.; DEMAI, F. M.; PRATA, M. Missão, concepções e práticas do

Grupo de Formulação e Análises Curriculares (Gfac): uma síntese do Laboratório de Currículo do Centro Paula Souza. set. 2016. Disponível em:

<http://www.cpscetec.com.br/cpscetec/arquivos/2014/missao.pdf> . Acesso em: 1 abr. 2016.

ARENDT, H. A condição humana. 12. ed. Rio de Janeiro: Forense Universitária, 2014.

BARBOSA, M. A. Sistema conceptual e sistema terminológico. TRADTerm: Revista do Centro Interdepartamental de Tradução e Terminologia, São Paulo: Humanitas, n. 7, p. 71-94, 2001.

. Etno-terminologia e terminologia aplicada: objeto de estudo, campo de aplicação. In: ISQUERDO, A. N.; ALVES, I. M. (Org.). As Ciências do Léxico: lexicologia, lexicografia, terminologia, v. 3. Campo Grande: Ed. UFMS; São Paulo: Humanitas, 2007. p. 433-445. 
BARROS, L. A. Curso Básico de Terminologia. São Paulo: Editora da Universidade de São Paulo, 2004. (Coleção Acadêmica, 54)

CABRÉ, M. T. La terminología: teoría, metodología, aplicaciones. Barcelona:

Editorial Antártida/Empúries, 1993.

. La terminología: representación y comunicación: elementos para una teoría de base comunicativa y otros artículos. Barcelona: Institut Universitari de Lingüística aplicada/Universitat Pompeu Fabra, 1999.

CUNHA, A. G. Dicionário etimológico Nova Fronteira da língua portuguesa. Rio de Janeiro: Nova Fronteira, 1986.

DEMAI, F. M. Processos de terminologização: descrição e análise da neologia da área de Educação do Campo. 2014. 417 f. Tese (Doutorado em Letras) - Faculdade de Filosofia, Letras e Ciências Humanas, Universidade de São Paulo, São Paulo, 2014.

EAGLETON, T. A ideia de cultura. 2. ed. São Paulo: Editora Unesp, 2011.

MEC (BRASIL, MINISTÉRIO DA EDUCAÇÃO). Educação profissional:

referenciais curriculares nacionais da educação profissional de nível técnico. Brasília:

MEC, 2000. Disponível em: <http://portal.mec.gov.br/setec/arquivos/pdf/introduc.pdf>. Acesso em: 05 fev. 2016.

Resolução CNE/CEB n. 3/ 2008, de 9 de julho - Dispõe sobre a instituição e implantação do Catálogo Nacional de Cursos Técnicos de Nível Médio. Brasília: MEC, 2008a. Disponível em: <http://portal.mec.gov.br/setec/arquivos/pdf/rceb003_08.pdf>. Acesso em: 1 abr. 2016.

Parecer CNE /CEB n. 11/ 2008, de 7 de julho - Proposta de instituição do Catálogo Nacional de Cursos Técnicos de Nível Médio. Brasília: MEC, 2008b. Disponível em: <http://portal.mec.gov.br/setec/arquivos/pdf/pceb011_08.pdf>. Acesso em: 1 abr. 2016.

SCOTT, M. WordSmith Tools. Oxford University. Programa de computador. Versão 4.0 e Versão 5.0.

TEMMERMAN, R. Sociocognitive Terminology Theory. In: Terminología y cognición. Barcelona: Institut Universitari de Lingüística Aplicada/Universitat Pompeu Fabra, 2001. 